\title{
Endocrinology 2017: the last 20years and prospects for the next decades
}

\section{Mini review}

As an invitation from Victoria Mosley for a 2-page opinion came I was wondering what could help colleagues to understand this current moment of Endocrinology in the world and predict our future. Inspired by the excellent article "Endocrinology-quo vadis" of our dearest colleague Prof. Dr. Helmut Schatz - an outstanding voice of German Endocrinology for the last decades - I decided to register the impressions of 10 years as Head of an Endocrinology post graduation in Brazil, the experience as 'Visiting Scholar' at the Harvard University (along with 4years of continuous experiences organizing Harvard's Courses for Brazilian colleagues, and finally an incipient experience at a Diabetology Department in Northern Germany. So I tell a story of the last 20years of Endocrinology in 3 countries I experienced working at: the United States, Brazil and Germany. A light forward and a lighthouse backwards on Endocrinology. These 20 years of experience in Endocrinology may not register the facts exactly as they objectively are, but rather from the standpoint of a doctor and professor who lives and loves Endocrinology for a while now.

\section{The situation in America}

The United States are nowadays the world's excellence center for new Endocrinology guidelines and researches, but this story did not begin these days: Robert H. Williams was a pioneer who in 1950 wrote the first edition of the current international compendium of Endocrinology worldwide. All new Endocrinologists devote most of their early studies to the newest edition of this book, now in the $13^{\text {th }}$ Edition (more than 65years!). Our most important Journal is based at Harvard ('The New England Journal of Medicine'), where recent studies such as EMPA-REG and LEADER were published. Harvard Teachers are main authors of guidelines that are followed by or used as main references by almost every national guideline of national endocrine societies throughout the world.

It seems like America will keep being the center of EvidenceBased Endocrinology for the next decades. Work and research in our field is not outcast by any other center in the world, although isolate initiatives in other Centers such as Europe (in subspecialties such as Diabetology, Adrenals and pituitary diseases), China ('Open Journals') and the Americas also contribute to enhance the scientific production of Endocrinology in the world.

America developed a program of continuing medical education (CME) and will keep working to attract all the best minds of the field to their headquarters (Mayo Clinic, HMS (Harvard Medical School) and so many others). Every young specialist (and every Endocrinologist 'to-be') should consider visiting an American Endocrinology service in order to understand how knowledge in our area is produced and built.

\section{Endocrinology in Germany}

In the wealthiest country of Europe Endocrinology acquires a very technical and own standard of science, which represents a critical
Volume 5 Issue I - 2017

Alberto K Arbex
Head of the post graduation in Endocrinology, Ipemed Brazil

Correspondence: : Alberto K Arbex, Post graduation in Endocrinology, IPEMED-Medical School Brazil, and Head of the Postgraduation in Endocrinology, Brazil, Email albertoarbex@gmail.com

Received: February 21, 2017 | Published: July 07, 2017

and questioning counterpoint to the knowledge produced in America. Following the very roots of the German Endocrinologists, which have always provided innovative and pioneering initiatives, current German guidelines and medical decisions do not simply follow their American colleagues' guidelines, but rather build their own standpoints in fields such as insulin therapy and diabetology, centered on European results of multi centered studies. This means that an American specialist would have to reinvent him-she if deciding to work in Germany, because Endocrinology in this country has its own rules and a very sharp view of how science should be made, mainly pointing out values such as ethics and the welfare of the population. It is therefore worth mentioning that every German citizen has the right to receive the best treatment available (through a national health plan that includes all citizens in Germany), which is quite the opposite of the American system of private health plans that prioritize those who may afford the best treatments.

It is also noteworthy that many German doctors/scientists of the $19^{\text {th }}$ and $20^{\text {th }}$ century described key Endocrine disorders such as Karl von Based (described Hyperthyroidism 80 years before Graves published it), Paul Langerhans (discovered in Berlin the cells that secrete insulin and had these named after him: "islets of Langerhans") and the first comprehensive Textbook of Endocrinology was published in Germany by Biedl (Lawrence-Moon-Biedl Syndrome) in 1910 with the name "Innere Sekretion" (Internal Hormones, in a free translation of the original name).

Germany is expected to keep a leading position in the field for the next years, especially in Europe. In this country 'Diabetology' is separated from Endocrinology and many specialists work solely with Diabetes, mainly because of the much higher prevalence of diabetes compared to other Endocrine Disorders, while a few centers produce specialists in Endocrinology. This division once again shows the German rational and pragmatic way of thinking and applying Medicine. It is in their Tradition and so it shall prevail.

\section{The situation in Brazil}

This South American country is my homeland and it is there that I firstly got interested in studying Endocrinology. They have a very organized national society with strong ties to the American Endocrinology guidelines but also centers of excellence such as those 
at São Paulo, Recife and Curitiba. Just like at any developing country, the difficulty to work in Endocrinology lies on the scarce sources of sources of health funding. The Brazilian population has a national health plan that lacks a minimal regularity. This means that diabetes control, for example, is inconstant and irregular and patients may receive an adequate treatment for a few months, before diving into several years of inaproppriate control and high $\mathrm{HbA1C}$ levels. This applies to all other clinical conditions within the Endocrinology field, which obviously do require constant control and follow-up.

Brazil also suffers of a worldwide burden of trends regarding "antiaging" medicine without further evidence of efficacy. This bring along risks of using medications and making diagnoses that do not exist in Evidence-based Medicine but rather stay borderline of 'alternative' therapies. So there are some excellence centers; amongst a majority of inconsistently treated patients. A broad crisis that affects health, economy and ethics' currently affects the country. This situation may not be too much different from that of any other developing country of the world when it comes to Endocrinology at all.

\section{Future prospects}

The last 20years have experienced a very rash development of innovative therapies and new targets for treating metabolic disorders. I try to specify some key points of Endocrinology nowadays.

a. Endocrinology will remain an interdisciplinary field and will increasingly include non-medical professionals as cutting-edge researchers and daily work force.

b. Education will increasingly be necessary for patients, such as Elliot Joslin already described one century ago regarding diabetes. Nowadays obesity is considered to be a chronic disease, and demands a long-time therapy and especially nutritional education.

c. Molecular Endocrinology is the key for the future of the specialty. Regardless of how the new Endocrinologists like or dislike the complex feedback mechanisms that belong to endocrine disorders, the new markers, cytokines and mediators are the future in fields such as thyroid cancers, special types of diabetes and insulin resistance and will surely evolve to become part of our daily practice.

d. Obesity and Diabetes will necessarily evolve to use the association of different medications - with different acting mechanisms - to reach the difficult goals of keeping stable BMIs and adequate $\mathrm{HbA} 1 \mathrm{c}$ levels among our patients. Obesity is already considered a chronic disease and should be treated this way.

e. Finally, themes such as the Endocrine disruptors are prone to become international fields of general concern and surpass the frontiers of Endocrinology. ${ }^{2,3}$ They represent a key target towards a better health in the world and encompass water and food safety standards. Endocrinology and public health are complementary areas and obesity, diabetes and thyroid disorders shall not be regarded solely as medical problems anymore but will need resolute and competent decisions by the governments, otherwise they shall remain unsolved challenges of public health.

\section{Endocrinology: a bright future}

These are some of the many reasons why Endocrinologists have a bright future ahead. Understanding Endocrinology as a broad field and keeping within the Evidences and the best practices available will provide a broad burden of opportunities to make this a better and healthier world. Many thanks to all our predecessors, those who made this moment of overcoming biological hazards possible. Endocrinology may still not be well known among patients as other clinical specialties are, but this fact is yet to be outcast by the bright future we expect. Endocrinology IS THE FUTURE.

\section{Acknowledgments}

None.

\section{Conflicts of interest}

The authors declare that there is no conflict of interest.

\section{References}

1. Schatz Helmut. Endocrinology-quo vadis? International Journal of Endocrinology and Metabolic Disorders. 2015;1(1):2.

2. Melmed S, Polonsky KS, Larsen PR, et al. Williams textbook of endocrinology. Elsevier Health Sciences, Netherlands. 2015.

3. Lucchese TA, Grunow N, Werner I, et al. Endocrine Disruptors and Fetal Programming. Open Journal of Endocrine and Metabolic Diseases. 2017;7(01):59. 